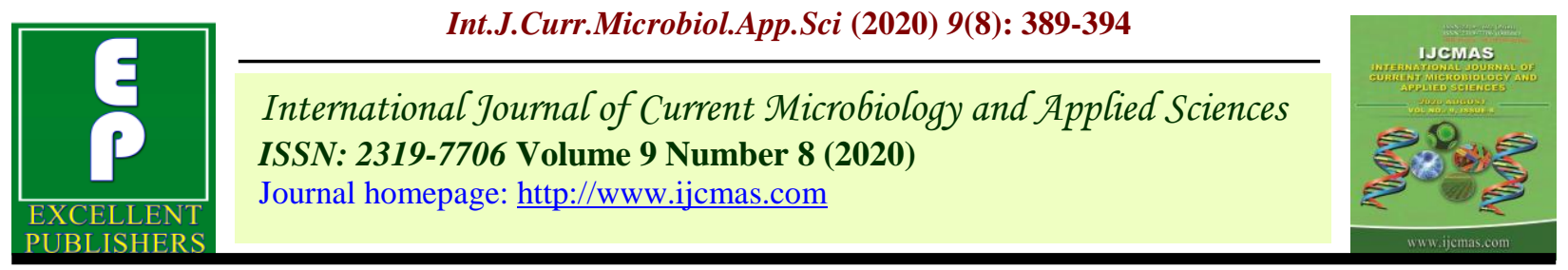

Original Research Article

https://doi.org/10.20546/ijcmas.2020.908.045

\title{
A Study on Demographic Profile of Rural Adults Identified with Lifestyle Diseases
}

\author{
Modi Ragini ${ }^{{ }^{*}}$, S. L. Kameswari ${ }^{1}$, R. Geetha Reddy ${ }^{1}$ and S. Suchiritha Devi ${ }^{2}$ \\ ${ }^{1}$ Department of Extension Education and Communication Management, Hyderabad. \\ Professor Jayashankar Telangana State Agricultural University, Telangana, India \\ ${ }^{2}$ Department of Foods and Nutrition, PG\&RC, Rajendranagar, Hyderabad, Professor \\ Jayashankar Telangana State Agricultural University, Telangana, India \\ *Corresponding author
}

\section{A B S T R A C T}

\section{Keywords \\ Lifestyle Diseases, Non-communicable diseases, Chronic diseases, Extension contact, Mass media exposure, Information seeking behaviour}

\section{Article Info}

Accepted:

10 July 2020

Available Online:

10 August 2020
The present study was undertaken to study the profile characteristics of rural adults identified with various lifestyle diseases. Total samples of 120 rural adults were selected through purposive random sampling method. Exploratory research design was used for the investigation by using a structured interview schedule. The data was analyzed using frequency, percentage and mean percent score. In the study, the results revealed that majority of the respondents were comprised of male $(55.83 \%)$, female $(44.17 \%)$, belonged to middle age group $(63.33 \%)$, married (93.68\%), were nuclear families (91.67\%), had medium family size $(60.83 \%)$, with primary education $(27.50 \%)$, had farming $(75.00 \%)$ as occupation, with marginal landholding (47.50\%), medium income group (44.17\%), had medium level of mass media exposure $(42.50 \%)$, medium extension contact $(50.00 \%)$ and medium information seeking behavior (44.17\%). Majority of the rural adults were identified with hypertension (71.67\%) followed by diabetes $(68.33 \%)$ and obesity (46.66\%) as the most identified lifestyle diseases.

\section{Introduction}

In this advancing world, lifestyle diseases are identified as the major threat to the population all across the world. Many organisations such as WHO (World Health Organisation), UNDP (United Nations Development Programme), ICMR Indian Council of Medical Research) and many state and central policies are laid to combat the death rate caused by lifestyle diseases.
Lifestyle diseases describes those diseases whose occurrence is predominantly based on daily habits of people and are a result of an unsuitable relationship of people with their living environment (Mukesh and Majumdar, 2009). Lifestyle diseases include diabetes, obesity, heart disease, stroke, pulmonary disease, metabolic syndrome and various types of cancer (Fatma, 2020). Lifestyle has widely linked with the growth of many 
prolonged non-communicable diseases (Joy Kumar and Sanjay, 2017). These are also known as chronic diseases tend to be of long duration and slow advancement of the ailments and combination of genetic, physiological, environmental and behaviours factors (WHO, 2018).

Hence, studying the demographic profile provides information about individuals who are representative sample of the target population for drawing generalization purposes to implement necessary plan of action to overcome the burden of lifestyle diseases.

The main objectives of this study includes to study the demographic profile of the rural adults and to identify various lifestyle diseases prevalent among the rural adults.

\section{Materials and Methods}

In the present study exploratory research design was followed. As the headquarters of investigator was Telangana state it was selected purposively enabling her easy approachability. Medak and Rangareddy districts were selected purposively based on the factsheet of National Family Health Survey (NHFS) 4 Data (2015-16) of Telangana State.

Out of two selected districts, two mandals from each district and two villages from each mandal covering 15rural adults from each village, thus constituting a total sample of 120 rural adults were selected for the present study. Purposive random sampling was adopted for sample selection with the criteria of involvement. The data was structured, formulated and categorized using qualitative and quantitative classification and subjected to statistical tests. The statistical tools were Frequency, Percentage and Mean percent score.

\section{Results and Discussion}

\section{Profile Characteristics of the Rural Adults}

Age

Table 1 indicates that majority $(66.33 \%)$ of the respondents belonged to middle age followed by young age $(25.83 \%)$ and old age $(22.50 \%)$. The results were supported by Shwetha (2018).

\section{Gender}

Table 1 indicates that majority $(55.83 \%)$ of the respondents were male followed by female $(44.17 \%)$. The results were supported by Rahman (2018).

\section{Marital Status}

Table 1 indicates that majority $(93.33 \%)$ of the respondents were married followed by unmarried $(4.17 \%)$ and widowed $(2.50 \%)$. Similarly the results were in line with the results of Gujar and Manisha (2017).

\section{Education}

Table 1 depicts that majority $(27.50 \%)$ of the respondents had primary school education followed by middle school (18.33\%), illiterates (17.50\%), high school (16.67\%), intermediate or diploma $(13.33 \%)$ and graduation and above $(6.77 \%)$. The results were in accordance with the results of Priyanka (2018).

\section{Family Type}

Table 1 indicates that majority $(55.83 \%)$ of the respondents were belonged to nuclear family followed by joint and extended $(44.17 \%)$. The results were supported by Shwetha (2018). 
Table.1 Distribution of rural adults according to their profile characteristics $n=120$

\begin{tabular}{|c|c|c|c|}
\hline S. No. & Category & Frequency (F) & Percentage (\%) \\
\hline 1. & \multicolumn{3}{|c|}{ Age } \\
\hline a) & Young (18-35) & 31 & 25.83 \\
\hline b) & Middle (35-55) & 76 & 63.33 \\
\hline c) & Old (Above 55) & \multirow{2}{*}{\multicolumn{2}{|c|}{ Gender }} \\
\hline \multicolumn{2}{|r|}{ (1) } & & \\
\hline a) & Male & 67 & 55.83 \\
\hline b) & Female & 53 & 44.17 \\
\hline \multicolumn{4}{|c|}{ 3. Marital Status } \\
\hline a) & Married & 112 & 93.33 \\
\hline b) & Un-married & 05 & 4.17 \\
\hline c) & Widowed & 03 & 2.50 \\
\hline \multicolumn{4}{|c|}{ 4. Family Type } \\
\hline a) & Nuclear & 110 & 91.67 \\
\hline b) & Joint & 09 & 7.50 \\
\hline c) & Extended & 01 & 0.83 \\
\hline \multicolumn{4}{|c|}{ 5. Family Size } \\
\hline a) & Small (up to 4) & 44 & 36.67 \\
\hline b) & Medium (5-8) & 73 & 60.83 \\
\hline c) & Large (more than 8) & 03 & 2.50 \\
\hline \multicolumn{4}{|c|}{ 6. Education } \\
\hline a) & Illiterate & 21 & 17.50 \\
\hline b) & Primary Education & 33 & 27.50 \\
\hline c) & Middle School & 22 & 18.33 \\
\hline d) & High School & 20 & 16.67 \\
\hline e) & Intermediate/Diploma & 16 & 13.33 \\
\hline f) & Graduation and above & 08 & 6.77 \\
\hline \multicolumn{4}{|c|}{ 7. Occupation } \\
\hline a) & Farmer & 90 & 75.00 \\
\hline b) & Agril. Labourer & 08 & 6.67 \\
\hline c) & Home Maker & 05 & 4.17 \\
\hline d) & Business & 13 & 10.83 \\
\hline e) & Government Employee & 01 & 0.83 \\
\hline f) & Others (Students) & 03 & 2.50 \\
\hline \multicolumn{4}{|c|}{ 8. Annual Income } \\
\hline a) & Low (Rs. 50,000 - Rs. 1 Lakh) & 48 & 40.00 \\
\hline b) & $\begin{array}{l}\text { Medium (Rs. 1Lakh - Rs. } 1.5 \\
\text { Lakhs) }\end{array}$ & 53 & 44.17 \\
\hline c) & $\operatorname{High}(\geq$ Rs.1,50,000) & 19 & 15.83 \\
\hline \multicolumn{4}{|c|}{ 9. Landholding } \\
\hline a) & Landless (0 ha) & 12 & 10.00 \\
\hline b) & Marginal (<0.5 ha) & 57 & 47.50 \\
\hline c) & Small (0.5 ha -1 ha) & 40 & 33.33 \\
\hline d) & Medium (1 ha $-1.5 \mathrm{ha})$ & 09 & 7.50 \\
\hline e) & Large $(\geq 1.5 \mathrm{ha})$ & 02 & 1.67 \\
\hline
\end{tabular}


Table. 2 Distribution of rural adults according to their extent of Mass Media Exposure $n=120$

\begin{tabular}{|r|l|c|l|}
\hline S. No. & Mass Media Exposure & Frequency (F) & Percentage (\%) \\
\hline a) & Low & 46 & 38.33 \\
\hline b) & Medium & 51 & 42.50 \\
\hline c) & High & 23 & 21.66 \\
\hline
\end{tabular}

Table.3 Distribution of rural adults according to their frequency of Extension Contact $n=120$

\begin{tabular}{|c|l|c|l|}
\hline S.No. & Extension Contact & Frequency & Percentage (\%) \\
\hline a) & Low (0-7) & 41 & 34.17 \\
\hline b) & Medium (7-14) & 60 & 50.00 \\
\hline c) & High (14-21) & 19 & 15.83 \\
\hline
\end{tabular}

Table.4 Distribution of rural adults according to their information seeking behavior $n=120$

\begin{tabular}{|r|l|l|l|}
\hline S. No. & Information seeking behaviour & Frequency & Percentage (\%) \\
\hline a) & Low (0 -7) & 48 & 40.00 \\
\hline b) & Medium (7-14) & 53 & 44.17 \\
\hline c) & High (14-21) & 19 & 15.83 \\
\hline
\end{tabular}

Table.5 Distribution of rural adults according to various identified lifestyle Diseases $n=120$

\begin{tabular}{|c|l|c|c|}
\hline \multirow{2}{*}{ S. No } & \multirow{2}{*}{ Lifestyle Diseases } & \multicolumn{2}{|c|}{ Presence of Lifestyle Diseases } \\
\cline { 3 - 4 } & & MPS & Rank \\
\hline $\mathbf{1 .}$ & Diabetes & 68.33 & II \\
\hline $\mathbf{2 .}$ & Hypertension & 71.67 & I \\
\hline $\mathbf{3 .}$ & Heart Diseases & 1.67 & VII \\
\hline $\mathbf{4 .}$ & Respiratory Diseases & 9.17 & IV \\
\hline $\mathbf{5 .}$ & Stress & 8.33 & V \\
\hline $\mathbf{6 .}$ & Obesity & 46.66 & III \\
\hline $\mathbf{7 .}$ & Osteoporosis & 4.17 & VI \\
\hline
\end{tabular}

Fig.1 Distribution of rural adults according to various identified lifestyle diseases

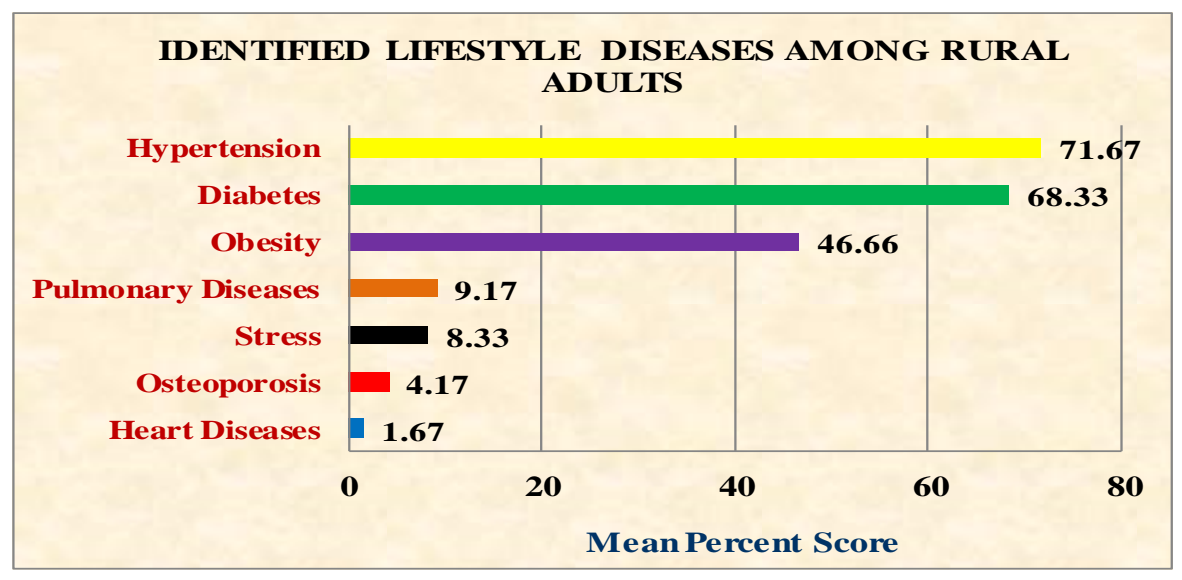




\section{Family Size}

Table 1 indicates that majority (55.83\%) of the respondents family size was small to $\mathrm{s}$ male and female (44.17\%). The results were supported by Shwetha (2018).

\section{Occupation}

It was evident from the table. 1 that three fourth of the majority (75.00\%) of respondents were belonged to farmer category followed by business person (10.83\%), agricultural labourer (6.67\%), home maker $(4.17 \%)$ student $(2.50 \%)$ and Government employee $(0.83 \%)$. The results were in line with the results of Avinash (2013).

\section{Annual Income}

The results in the Table.1clearly indicated that maximum number $(44.17 \%)$ of the respondents were belonged to medium annual income group followed by 40.00 per cent of the respondents were belonged to low annual income group and $15.83 \%$ of the respondents were belonged to high annual income group. Similar results were found by Gayatri (2017).

\section{Landholding}

Table. 1 indicated that nearly half $(47.50 \%)$ of the respondents had marginal landholding (< $0.5 \mathrm{ha}$ ) followed by 33.33 per cent of the respondents had small land holding $(0.5$ ha $1 \mathrm{ha}), 10.00$ per cent of the respondents were landless ( 0 ha), 7.50per cent of the respondents had medium land holding (1 ha$1.5 \mathrm{ha})$ and only 1.67 per cent of the respondents had large landholding ( $\geq 1.5 \mathrm{ha}$ ). Similar results were found by Anita Rani (2019).

From table 2 it was evident that majority $(42.50 \%)$ of the respondents had medium level of mass media exposure followed by low level (38.33\%) and high level (21.66\%) of mass media exposure. Similar results were found by BhanuPratap (2019).

From table 3 it could be found out that half of the respondents $(50.00 \%)$ had medium extension contact followed by low $(34.17 \%)$ and high $(15.83 \%)$ level of extension contact. Passive participation of women was the most inhibited reason for medium level contact with extension personnel. The findings were similar with the findings of Bidve (2019).

From table 4 it was clearly understood that majority $(44.17 \%)$ of the respondents had medium extent of information seeking behaviour followed by low $(40.00 \%)$ and high $(15.83 \%)$ extent of information seeking behaviour.

The reason for these results of medium extent of information seeking behaviour may be due to illiteracy and less social participation those encountered them to get information from other sources. It was also observed family members were the highest source of information obtained by the respondents. The results were in line with the results of Rohitash (2017).

\section{Identification of Lifestyle Diseases}

From table. 2 revealed that majority of the rural adults were identified with "hypertension" (MPS 71.67) as the most suffered lifestyle disease among the respondents. The second most identified lifestyle disease suffered by rural adults was "diabetes" (MPS 68.33), followed by "obesity" (MPS 46.66), "respiratory diseases" (MPS 9.17), "stress" (MPS 8.33), "osteoporosis" (MPS 4.17) and "heart diseases" (1.67) which were ranked third, fourth, fifth, sixth and seventh respectively (Fig.1.). Similar results were reported by Vennu et al., (2019). 
In conclusion the lifestyle diseases were found to be the foremost causes of morbidity in the country and across the world. Hypertension, diabetes, and obesity were the majorly identified lifestyle diseases among the rural adults. These conditions may be linked with factors such as age, socioeconomic status and personal habits of the adults. The development of multimedia modules and related interventions may enhance the knowledge and create awareness on the need based information among the people on lifestyle diseases that are prevalent among them. Individual responsibility towards proper diet, regular exercise and avoiding unhealthy personal habits can be a necessary step intended to combat the burden of various lifestyle diseases. Government plays a positive role for better policy formulation.

\section{References}

Gupta A, Goyal N, Jindal A K, Kumar R (2017). Study of lifestyle diseases among workers of an ammunition factory.Journal of Marine Medical Society; 19:43-7

Pappachan M. J, 2011. Increasing prevalence of lifestyle diseases: high time for action. The Indian journal of medical research, 134(2), 143-145.

Priya. P, 2016.Assessment of nutritional status and life style diseases among different income groups, M. Sc thesis, Kerala Agricultural University
Shaji. K, 2013. Lifestyle diseases in Kerala: An analysis of socio economic status, consumption pattern and adolescent obesity in Kottayam District, Ph.D. Thesis, Mahatma Gandhi University, Kottayam, Kerala

Sharma, M., \&Majumdar, P. K. (2009). Occupational lifestyle diseases: An emerging issue. Indian journal of occupational and environmental medicine, 13(3), 109-112. https://doi.org/10.4103/00195278.58912

Tripathy J.P. Research priorities in noncommunicable diseases in developing countries: time to go beyond prevalence studies. Public Health Action. 2018; 8(2):98-99. doi:10.5588/pha.18.0023

Vennu, V., Abdulrahman, T. A., \& Bindawas, S. M. (2019). The Prevalence of Overweight, Obesity, Hypertension, and Diabetes in India: Analysis of the 2015-2016 National Family Health Survey. International journal of environmental research and public health, 16(20), 3987.https://doi.org/10.3390/ijerph162 03987

World Health Organisation. Noncommunicable diseases. 1 June 2018. https://www.who.int/news-room/factsheets/detail/ noncommunicablediseases

\section{How to cite this article:}

Modi Ragini, S. L. Kameswari, R. Geetha Reddy and Suchiritha Devi, S. 2020. A Study on Demographic Profile of Rural Adults Identified with Lifestyle Diseases. Int.J.Curr.Microbiol.App.Sci. 9(08): 389-394. doi: https://doi.org/10.20546/ijcmas.2020.908.045 